\title{
MICROCRÉDITO COMO ELEMENTO DE TRANSFORMAÇÃO SOCIAL: UM ESTUDO SOBRE AS CONTRIBUIÇÕES DO CREDIAMIGO NO MUNICÍPIO DE JUAZEIRO, BA
}

\author{
MICRO-CREDIT AS AN ELEMENT OF SOCIAL CHANGE: \\ A STUDY ON THE CONTRIBUTIONS OF THE CREDIAMIGO \\ ON MUNICIPALITY OF JUAZEIRO, BA
}

\author{
Kleber Avila Ribeiro ${ }^{1}$, Deise Cristiane do Nascimento ${ }^{2}$, \\ Anne Karinne Gomes de Barros Rodrigues ${ }^{3}$ e Mona Mirelle Castro Reis ${ }^{4}$ \\ Recebido em: 03/05/2013 \\ Aprovado em: 26/03/2014
}

\section{RESUMO}

Este trabalho tem por objetivo mostrar como o microcrédito, em especial, o Crediamigo do banco do Nordeste, vem se destacando como importante fonte de recursos para os pequenos empreendedores no município de Juazeiro, BA. Nos últimos anos, essa prática de microfinanças vem alcançando destaque como instrumento no combate à exclusão social e à pobreza, contribuindo para o seu desenvolvimento social. Utilizou-se como metodologia a pesquisa bibliográfica para auxiliar na fundamentação teórica e na obtenção de dados históricos, além da pesquisa de campo descritiva com aplicação de questionários junto aos tomadores de recursos e à instituição financeira responsável pela sua concessão. Constatou-se, através desta pesquisa, que o microcrédito propiciou significativas mudanças por meio de melhorias na atividade exercida pelos tomadores de crédito e do aumento de sua qualidade de vida.

Palavras-chave: Empreendedor; Microcrédito; Desenvolvimento econômico.

\section{Introdução}

No início da década de 90, o Brasil passou por profundas mudanças estruturais que culminaram na precarização das relações de trabalho, fazendo com que o nível de desemprego aumentasse consideravelmente. Isso se

\begin{abstract}
This work aims to show how microfinance, especially Crediamigo bank in the Northeast, has become an important resource for small entrepreneurs in Juazeiro-BA, whereas in recent years, this practice of microfinance is reaching Featured as a tool in combating social exclusion and poverty alleviation, as well as acting as a transformative social communities contributing to their social development. Was used as the research methodology literature to assist in obtaining theoretical and historical data, along with field research with descriptive questionnaires along to borrowers and the financial institution responsible for granting the appeal. It was found through this research, which led to significant changes microcredit through improvements in the activity exercised by borrowers and also in their quality of life.
\end{abstract}

Keywords: Entrepreneurs; Microfinance; Economic development.

deu uma vez que muitos trabalhadores perderam seus trabalhos formais, migrando para a informalidade e juntando-se àqueles excluídos historicamente do mercado formal, ou seja, àquelas pessoas que sempre atuaram no mercado informal. Tais mudanças estruturais foram provocadas pela convergência de

\footnotetext{
' Mestrando em Planejamento Territorial e Desenvolvimento Social pela Universidade Católica de Salvador (UCSal), Brasil. E-mail: kleberavilar $a$ gmail.com. ${ }^{2}$ Doutoranda em Administração pela Universidade Positivo, Brasil. Administradora na Companhia Paranaense de Energia (COPEL). E-mail: gmail.com. 'Doutoranda em Administração pela Universidade Positivo, Brasil. Administradora na Companhia Paranaense de Energia (COPEL). E-mail: veronica.eberle@gmail.com

${ }^{3}$ Mestranda em Planejamento Regional e Urbano pela Universidade Salvador (UNIFACS), Brasil. Coordenadora e professora auxiliar do curso de Economia da Faculdade de Ciências Aplicadas e Sociais de Petrolina (FACAPE). E-mail: deise.nascimento@facape.br.

${ }^{3}$ Bacharela em Administração de Empresas pela Faculdade de Ciências Aplicadas e Sociais de Petrolina (FACAPE), annekgbr@hotmail.com;

${ }^{4}$ Bacharela em Administração de Empresas pela Faculdade de Ciências Aplicadas e Sociais de Petrolina (FACAPE),moninha89@hotmail.com;
} 
três fatores: i) a globalização; ii) a reestruturação da cadeia produtiva nacional; e iii) o processo de privatização das empresas estatais.

Tais acontecimentos propiciaram, de forma intensiva, o surgimento de micro e pequenos empreendimentos formais e informais. Esses, denominados empreendimentos solidários, passaram a atuar como instrumento de geração de emprego e renda, contribuindo para o desenvolvimento econômico e social do território onde se encontram.

A falta de informações e dados básicos do empreendimento, aliado ao fato de muitos deles não possuírem um planejamento financeiro para curto e longo prazo, pode resultar problemas relevantes, enfrentados, particularmente, pelo pequeno empreendedor, fazendo com que este, muitas vezes, acabe tomando decisões equivocadas e de consequências indesejáveis. Nesse contexto, o uso de capital de terceiros para a implementação ou até mesmo para a sobrevivência do negócio parece ser a única saída para os pequenos empreendedores. Saída essa que é incentivada pela criação de programas e linhas de financiamento especiais para esse público, como, por exemplo, o Programa Nacional de Microcrédito Produtivo e Orientado (PNMPO), instituído pela Lei 11.110, de 25 de abril de 2005.

O microcrédito é a concessão de empréstimos de baixo valor a pequenos empreendedores informais e microempresas sem acesso ao sistema financeiro tradicional, principalmente por não terem como oferecer garantias reais. Destina-se à produção (capital de giro e investimento em capital fixo) e é concedido com o uso de uma metodologia específica que consiste, primeiramente, na concessão assistida do crédito. Ao contrário do que acontece no sistema financeiro tradicional, em que o tomador do recurso vai à instituição financei$\mathrm{ra}$, nas instituições de microcrédito, os agentes de crédito vão até o local onde o candidato ao crédito exerce sua ativida- de produtiva, para avaliar suas necessidades e as condições de seu empreendimento, bem como as possibilidades de pagamento. Após a liberação do crédito, um profissional passa a acompanhar a evolução do negócio.

O microcrédito democratiza o acesso ao crédito, acesso esse a que grande parte dos brasileiros está excluída. A geração de trabalho e renda para as famílias de baixo poder aquisitivo favorece alternativas de ocupação e aumento de produtividade. $\mathrm{O}$ impacto social do microcrédito resulta em melhorias nas condições de saúde, habitação e alimentação (CAVALCANTE, 2011).

Tendo isso em vista, buscou-se verificar as contribuições do uso desse recurso em micro e pequenos empreendimentos no município de Juazeiro, BA, em relação a aspectos econômicos, culturais e sociais.

Dessa forma, este artigo apresenta o microcrédito como uma ferramenta para a manutenção e o desenvolvimento de pequenos negócios, com especial destaque ao Crediamigo, que é o programa de microcrédito do Banco do Nordeste. Criado em 1988, o Crediamigo, tem por objetivo oferecer crédito aos pequenos empreendedores de baixa renda da região Nordeste e do norte de Minas Gerais e do Espírito Santo. Esse programa trabalha com a metodologia de grupos solidários e, simultaneamente à concessão de crédito, oferece capacitação gerencial para os tomadores.

As experiências do microcrédito atestam sua importância para a sobrevivência e o crescimento de micro e pequenos empreendimentos, fazendo com que haja o desenvolvimento local. Por ser uma modalidade de crédito bastante utilizada na região, este estudo propõe-se a mostrar o Crediamigo como um instrumento capaz de promover e auxiliar na transformação social para a cidade de Juazeiro, como também apresentar as mudanças ocorridas para os tomadores de crédito.

Os microempreendimentos so- 
frem com as barreiras de acesso ao crédito do sistema tradicional e, assim, necessitam usar os seus lucros para se autofinanciarem. Muitos acabam fechando as portas por falta de recursos para investir em seus negócios.

A escassez de crédito é muito mais severa para os micro e pequenos empreendimentos. Com isso, há uma restrição considerável de sua capacidade produtiva, que ocasiona um impacto negativo na geração de receitas e na ampliação de suas atividades, cuja conseqüência é o surgimento de um ciclo econômico-financeiro restritivo (CAVALCANTE, 2004, p. 43).

Assim, o microcrédito surge para atender a essas empresas que não têm acesso ao sistema financeiro tradicional, uma vez que não oferecem garantias reais e por não terem uma gestão eficiente profissional.

Por meio da metodologia própria direcionada ao perfil e às necessidades dos empreendedores, o microcrédito estimula as atividades produtivas e as relações sociais, gerando mais emprego e renda, incentivando a responsabilidade, a autoestima e a autossuficiência econômica das pessoas. $\mathrm{O}$ microcrédito é, assim, reconhecido e enfatizado por organismos internacionais, particularmente pelo Banco Mundial, pelo Banco Interamericano de Desenvolvimento e pela UNICEF, como o instrumento de maior abrangência às comunidades mais pobres e, portanto, de promoção de mudanças sociais.

$\mathrm{O}$ crédito concedido aos empreendedores é destinado para investimento e para capital de giro. De acordo com Leite (2009), a concessão de microcrédito aos potenciais empreendedores pode trazer importantes consequências para a renda e o emprego das regiões. A oferta de serviços adequados aos microempreendedores de baixa renda tem um efeito multiplicador bastante positivo na economia e nas condições sociais da região abrangida. Em curto prazo, contribui para a geração de renda e, em médio e longo prazo, dinamiza e potencializa a inserção de uma parcela informal da economia.

$\mathrm{O}$ apoio aos pequenos empreendedores é uma das formas mais importantes e efetivas de incentivar o desenvolvimento local. A concessão de crédito para pequenos empreendimentos é uma das ferramentas fundamentais para dar condições ao desenvolvimento de novos negócios, emergentes ou não, que possam ser concretizados a partir de idéias preexistentes ou de oportunidades de negócios que surjam no mercado (MARTINELLI, 2004).

Segundo o coordenador do Programa Nacional de Microcrédito Produtivo Orientado (PNMPO) do Governo Federal, Almir da Costa Pereira (Agência Brasil, 2007), os empréstimos melhoram a qualidade de vida dos pequenos empreendedores. Pereira ratifica o papel do microcrédito, salientando que todo empreendimento que recebe o investimento tem como impacto direto a ampliação do estoque de mercadorias disponíveis ao empreendimento e, consequentemente, à comunidade do entorno. $\mathrm{O}$ rendimento de um empreendedor apoiado pelo microcrédito após dois anos, por exemplo, duplica. Esse resultado repercute em mais serviços prestados à comunidade, melhoria na alimentação e na proteção à saúde, maior atenção à educação e aumento da capacidade de consumo.

\section{Contextualização histórica}

A primeira experiência com microcrédito aconteceu no sul da Alemanha, em 1846. Após um rigoroso inverno, o pastor Raiffeinsen, sensibilizado com a situação de endividamento dos fazendeiros locais, provocado pela aquisição de empréstimos junto aos agiotas, resolveu conceder-lhes farinha de trigo para que, com a fabricação e 
comercialização do pão, destinassem uma parcela do lucro resultante desta atividade ao pagamento de suas dívidas. Essa experiência ficou conhecida como Associação do Pão (BARONE, 2003).

Há algumas experiências que foram precursoras do microcrédito, porém, segundo Barone (2003), o grande acontecimento que desenvolveu, difundiu e serviu de modelo para popularizar o microcrédito foi a experiência iniciada em 1976, em Bangladesh, pelo professor Muhamad Yunus. Ao notar que os pequenos empreendedores das aldeias próximas, localizadas no entorno da universidade onde lecionava, eram reféns dos agiotas, o professor Yunus começou a emprestar-lhes pequenas quantias do seu próprio bolso, a princípio, sem a cobrança de qualquer tipo de encargo financeiro.

Bem-sucedida, a ação do professor Yunus culminou na criação do Grameen Bank (Banco da Aldeia), em 1978, considerada a primeira instituição financeira a lidar com microcrédito no mundo. Inicialmente, os recursos que seriam destinados para prover as atividades de microcrédito originavam-se da ajuda dos bancos privados e internacionais por meio de financiamentos e doações. As primeiras operações restringiam-se a pequenas quantias sem a cobrança de juros; o campo de atuação do Grameen Bank ateve-se a 35 mil povoados, contemplando 2,1 milhões de pessoas (das quais $94 \%$ eram mulheres) e movimentando 1,6 bilhões de dólares com índice de inadimplência inferior a $5 \%$.

Experiências de sucesso também ocorreram na América Latina, a exemplo do Banco Solidariedade S.A, na Bolívia, propiciando o surgimento de outras experiências com a concessão de microcrédito, como o primeiro banco comercial pautado em bases lucrativas neste segmento, atendendo cerca de 70.000 clientes (dos quais $70 \%$ são mulheres) e exercendo, assim, a liderança no desenvolvimento do microcrédito nas áreas rurais da Bolívia (NERI, 2008).

\subsection{O microcrédito no Brasil}

O microcrédito no Brasil iniciouse em 1973 com a criação do Programa Uno, conhecido como a União Nordestina de Assistência a pequenas organizações, nos municípios de Recife, PE e Salvador, BA, por iniciativa e com assistência técnica da organização não governamental Accion International, na época AITEC, e com a participação de entidades empresariais e bancos locais.

O programa UNO era uma organização não governamental especializada em microcrédito e capacitação para trabalhadores de baixa renda do setor informal, cujas operações eram lastreadas por uma espécie de "aval moral". Os recursos iniciais vieram de doações internacionais e, posteriormente, foram incrementados por outras linhas de crédito (BARONE et al., 2002 , p. 15). O programa UNO chegou a financiar inúmeros microempreendimentos nos estados de Pernambuco e da Bahia, formando milhares de profissionais especialistas em crédito para o setor informal e chegando a ser apontado como referência para a expansão dos programas de microcrédito na América Latina. Apesar do êxito inicial, o programa UNO chegou ao seu final após dezoito anos de atuação, pois não levou em consideração a autossustentabilidade como parte fundamental de suas políticas, o que poderia ter sido assegurado com base em duas medidas: i) transformação das doações recebidas em patrimônio financeiro, ou seja, empréstimo a juros de mercado para que pudessem gerar receitas e capitalizar a entidade, promovendo a sua sustentabilidade; e ii) negociação com as entidades parceiras da cobrança de juros reais em todas as linhas de crédito em que operava, obtendo ganhos para prover sua capitalização.

Em 1987, foi criado o Centro de Apoio aos Pequenos Empreendimentos Ana Terra (CEAPE/RS), em Porto Alegre, RS. O Centro Ana Terra, fundado na forma de organização não governamental, contou com o apoio do Banco Interamericano de Desenvolvimento 
(BID) e da Inter-American Foundation (IAF), que aportaram recursos para os financiamentos. O sucesso do Centro resultou na sua reprodução em vários estados brasileiros, dando origem, atualmente, a doze Centros de Apoio aos Pequenos Empreendimentos.

Outras experiências que marcaram a história do microcrédito no Brasil foram o Banco da Mulher, que, associado ao Women's World Bank, é uma rede de ONG's que atende a microempresários de todo o Brasil e a Portosol- Instituição Comunitária de Crédito, criada em 1995 com o apoio dos governos municipal de Porto Alegre e estadual do Rio Grande do Sul e da agência de assistência técnica alemã GTZ, entre outros.

Há, também, o Vivacred, criado em 1997 com o apoio de uma ONG da cidade do Rio de Janeiro (Viva Rio). O Vivacred trabalha no sentido de diminuir a violência e aumentar as oportunidades financeiras para a população carente do Rio. O financiamento inicial foi fornecido pela Fininvest, pelo BNDES e pelo BID.

Em 1998, foi criado o Crediamigo, programa de microcrédito do Banco do Nordeste, com o objetivo de oferecer crédito aos pequenos empreendedores de baixa renda da região Nordeste e do norte de Minas Gerais e do Espírito Santo.

Em 2001, o Serviço Brasileiro de Apoio a Micro e Pequena Empresa (SEBRAE) iniciou sua atuação no setor de microcrédito, com a finalidade de aumentar as oportunidades de acesso ao crédito para pequenos empreendimentos, sobretudo, os informais.

$\mathrm{O}$ cenário atual mostra que a indústria de microcrédito tem se apresentado como uma alternativa para a oferta de crédito no país e um elemento importante para cobrir as deficiências do Sistema Financeiro Nacional (SFN), propiciando às pessoas mais pobres acesso às linhas de capital produtivo, conduzindo -as ao caminho da porta de saída estrutural da pobreza (NERI ,2008) e provocando mudanças econômicas, pessoais, sociais e políticas (YUNUS, 2008).

\subsection{O Crediamigo}

O Programa de Microcrédito Produtivo Orientado do Banco do Nordeste, denominado Crediamigo, oferece crédito popular aos microempreendedores que desenvolvem atividades relacionadas à produção, à comercialização de bens e à prestação de serviços e que atuam, em sua maioria, no setor informal da economia. Concede empréstimos de forma rápida e de pequenos valores, beneficiando empreendedores que têm algum negócio de pequeno porte e precisam de dinheiro para tocar o seu empreendimento, além de oferecer assessoria empresarial para auxiliar o empreendedor a organizar e controlar melhor a sua atividade.

Segundo estudos do Instituto Brasileiro de Ética Concorrencial (ETCO), em parceria com a Fundação Getúlio Vargas (FGV), estima-se que no Brasil a economia subterrânea, ou informal, movimentou R\$ 578 bilhões em 2009, ou seja, $18 \%$ do Produto Interno Bruto brasileiro, valor que é superior ao PIB da Argentina (cerca de R $\$ 560$ bilhões) (LEITE, 2009).

No Nordeste brasileiro, segundo dados do PNAD ${ }^{5}$ (2005), os trabalhadores por conta própria e empregadores urbanos correspondem a cerca de 4,5 milhões de pessoas, aproximadamente, gerando um lucro anual agregado de $\mathrm{R} \$ 32,4$ bilhões e uma renda agregada de R $\$ 37$ bilhões, equivalendo a $22 \%$ e $25 \%$, respectivamente, da renda agregada de todas as fontes do Nordeste (NERI, 2008, p. 71-72).

$\mathrm{Na}$ região Nordeste, houve um crescimento diferenciado do crédito popular orientado, o que, segundo Neri (2008), pode ser explicado pela implantação do programa de microcrédito produtivo orientado do Banco do Nordeste

\footnotetext{
${ }_{5}^{5}$ Programa Nacional por Amostra de Domicílios - IBGE. Obtém informações anuais sobre características demográficas e socioeconômicas da população (como sexo, idade, educação, trabalho e rendimento), características dos domicílios e, com periodicidade variável, informações sobre migração, fecundidade, nupcialidade, entre outras.
} 
do Brasil S.A., denominado Crediamigo. Esse programa tem como base a metodologia de crédito em grupo solidário desenvolvida pelo Gramenn Bank (Bangladesh) e seu fundador Muhanmad Yunus, ganhadores do Nobel da Paz de 2006 (NERI, 2008, p. 13-16).

O Crediamigo está presente em 1.878 municípios da área de atuação do Banco (Região Nordeste, norte de Minas Gerais e do Espírito Santo, Brasília, Belo Horizonte e Rio de Janeiro), com 943.534 clientes ativos. $\mathrm{O}$ atendimento ocorre por meio de uma estrutura logística que dispõe de 173 agências e 173 postos de atendimento a clientes, com 3.821 colaboradores operacionalizando o programa nestas unidades (BACEN, 2011).

Em 2008, já ofertava sozinho mais microcrédito do que todos os outros programas brasileiros juntos, ocupando mais de $60 \%$ do mercado brasileiro de microcrédito, o que o intitula como o maior programa de microcrédito orientado do Brasil (NERI, 2008, p. 41).

Segundo o Balanço Social de 2009 , era o maior programa do gênero na América do Sul e o segundo nas Américas. Em 2010, atinge o posto de melhor Instituição da América Latina e Caribe, ganhando o Prêmio BID Excelência em microfinanças de Melhor Instituição Microfinanceira - 2010.

Seus produtos são adaptados ao cliente de acordo com suas possibilidades e necessidades, atendendo aos mais diversos perfis de interesse. Além dos produtos, o Crediamigo oferece serviços de assessoria empresarial para melhorar a capacidade gerencial dos clientes por meio de orientação em campo prestada pelos assessores e cursos de aperfeiçoamento gerencial.

O Crediamigo oferece diversos produtos:

- O Crescer Solidário destina-se à aquisição de matéria-prima, mercadorias e pequenos equipamentos. Os empréstimos variam de $\mathrm{R} \$ 100,00$ a $\mathrm{R} \$ 1.100,00$ para bancos comunitários e de $\mathrm{R} \$$ 100,00 a $\mathrm{R} \$ 2.000,00$ para grupos solidários. A garantia é formada por grupos solidários de 3 a 10 pessoas ou bancos comunitários de 15 a 30 pessoas. O prazo de pagamento fixo e mensal é de 4 a 12 meses;

- O Crescer Individual destina-se a investimentos para a aquisição de máquinas, equipamentos e reformas. Os empréstimos variam de $\mathrm{R} \$ 300,00$ a R $\$ 8.000,00$ em grupo de 15 a 30 pessoas, com prazo de pagamento fixo e mensal de até 36 meses sem carência e garantia coobrigado. Para ter acesso a esse crédito, o empreendedor precisa ter um negócio próprio estabelecido há no mínimo seis meses;

- O giro complementar é destinado a recursos para aquisição de matéria-prima e mercadorias. Os empréstimos variam de $\mathrm{R} \$$ $2.100,00$ até $\mathrm{R} \$ 15.000,00 \mathrm{com}$ pagamento fixo e mensal de até 12 meses. A garantia é formada por grupos solidários de 3 a 10 pessoas ou bancos comunitários de 15 a 30 pessoas. O empreendedor precisa ter um negócio próprio estabelecido há seis meses;

- O seguro de vida garante o pagamento de indenização aos beneficiários do seguro caso venha a falecer por morte de qualquer causa, com prêmio no valor de $\mathrm{R} \$ 25.000,00$, pago em parcela única. Capital Segurado de R\$ 3.000,00 e Auxílio Funeral de R\$ 840,00 . Participação em quatro sorteios mensais de R $\$ 1.500,00$;

- A orientação empresarial e ambiental por meio dos assessores de crédito, oferecendo noções básicas aos clientes sobre vendas, qualidade, planejamento, crédito, controle financeiro e meio ambiente, com o apoio de cartilhas que abordam esses temas. 
$\mathrm{O}$ cliente recebe uma cartilha no momento do desembolso do crédito;

- A conta corrente é isenta de taxa de abertura e manutenção, com movimentação por meio de cartão magnético;

- O Seguro prestamista oferece proteção no caso de morte no decorrer da operação;

$\mathrm{O}$ aspecto de sustentabilidade, tanto do ponto de vista financeiro do Programa quanto das melhorias acarretadas nas vidas dos clientes, situa o Crediamigo como uma das principais políticas públicas do Brasil e como o programa de microcrédito modelo para o programa Crescer, criado recentemente pelo governo federal.

Outra característica de destaque no Programa Crediamigo é que ele é autofinanciador: não recebe benefícios fiscais, já que o funding é de mercado e todas as demais despesas administrativas são cobertas pelas receitas geradas pelos juros cobrados dos clientes (NERI, 2008).

A partir das informações sobre o Programa Crediamigo expostas até aqui, é possível compreender o importante papel que este desempenha enquanto ação fomentadora da geração de emprego e renda, considerado por Melo Neto e Froes (1999) como uma das atividades que mais agregam valor à comunidade. O Programa contribuiu para que $60,8 \%$ dos seus beneficiários saíssem da faixa de pobreza (NERI, 2008).

\section{Procedimentos metodológicos}

O universo investigado foi composto por microempreendedores residentes no município de Juazeiro que são clientes ativos do programa Crediamigo, além do coordenador local do programa, Fábio Gomes.

O território objeto deste estudo (Figura 1) encontra-se localizado no semiárido da região Nordeste, com uma área de $6.500,6 \mathrm{~km}^{2}$. A população do território estimada para 2013 é de 214.748 habitantes (IBGE, 2010), apresentando uma densidade populacional de 30,45 $\mathrm{hab} / \mathrm{km}^{2}$. A área pertence à região integrada de desenvolvimento econômico (RIDE) do polo Petrolina, PE e Juazeiro, BA e ao território de identidade Sertão do São Francisco, BA. Além de destacarse no cenário nacional pela fruticultura irrigada e a pela produção de vinhos de mesa, Juazeiro chama a atenção pela prática da caprino-ovino cultura.

A fim de criar subsídios teóricos para a posterior análise da situação do microcrédito no município de Juazeiro, realizou-se, primeiramente, uma pesquisa bibliográfica em livros, revistas, artigos de jornais e na internet. A pesquisa propriamente dita caracterizou-se como uma pesquisa de campo descritiva. Para Moraes (1990), "pesquisas descritivas expõem características de determinada população e/ou determinado fenômeno".

Para a coleta de dados e informações necessárias à análise, utilizaram-se informações obtidas junto ao próprio Banco do Nordeste de Juazeiro, por meio do coordenador do Crediamigo e do fornecedor de microcrédito, e junto aos tomadores de microcrédito. Para Malhotra (2006), as perguntas estruturadas especificam o conjunto de respostas alternativas e o formato da resposta. Ainda na concepção do autor, as perguntas de múltipla escolha oferecem um elenco de respostas, podendo ser escolhida uma ou mais alternativas.

O tamanho da amostra foi definido com base na estimativa dos clientes. Sendo assim, para determinar a amostragem a partir da população da qual a amostra foi extraída, utilizaram-se métodos de amostragem probabilística que, de acordo com Lakatos e Marconi (2006), compensa erros amostrais, dando ao estudo maior representatividade e significância à amostra. Para originar o tamanho da amostra com base na estimativa da proporção populacional, uti- 
lizou-se a equação 01 , que determina que se substituam os valores populacionais por valores amostrais $\mathrm{p}^{\wedge} \mathrm{e} \mathrm{q} \mathrm{q}^{\wedge}$. Segundo Levine et alli (2000), como $\mathrm{p}^{\wedge} \mathrm{e}$ $\mathrm{q}^{\wedge}$ são desconhecidos, substituem-se $\mathrm{p}^{\wedge}$ e q^ por 0,5 , obtendo a seguinte estimativa, a partir da equação 01 :

$$
n=\frac{(Z a / 2)^{2} p \cdot q}{E^{2}}
$$

$\mathrm{n}=$ número de indivíduos de amostra;

$Z \alpha / 2=$ valor crítico que correspondente ao grau de confiança desejado. Para $90 \%$ de confiança, o valor crítico $Z \alpha / 2=$ 1,645

$p=$ proporção dos indivíduos que pertence à categoria que se deseja estudar; $q=$ indivíduos que não pertencem à categoria $(q=1-p)$; para este caso, substitui-se e por $\mathrm{p}^{\wedge}=0,5$ e $\mathrm{q}^{\wedge}=0,5$, pois se admite que os mesmos sejam desconhecidos;

$E=$ erro máximo da estimativa; é a diferença entre um resultado amostral e o verdadeiro resultado populacional. Tais erros resultam de flutuações amostrais aleatórias. $\quad Z \alpha / 2=90 \%$, p.q $=0,25, E$ $=15 \%$.

$$
\begin{aligned}
& =\frac{(0,90)^{2} 0,5 \cdot 0,5}{0,15^{2}} \\
& n=\frac{0,6765}{0,0225} \\
& n=30
\end{aligned}
$$

Com um nível de confiança de $90 \%$, o resultado da pesquisa é considerado satisfatório e significativo, pois tem uma estimativa de erro de $15 \%$.

Os entrevistados, de acordo com o cálculo, compreendem um total de 30 clientes ativos. Já que os clientes têm atendimento personalizado no seu local de trabalho e raramente visitam o banco, a melhor alternativa para a aplicação dos questionários foi via telefone, permitindo a obtenção de todas as informações necessárias para a realização da pesquisa. Os entrevistados residem em diversos municípios, como Curaçá, Sobradinho, Sento Sé, Uauá, Casa Nova e Juazeiro.

A pesquisa foi realizada em setembro e outubro de 2011, por meio da aplicação de questionário com 16 questões a 30 pessoas, representando uma amostra de, aproximadamente, $10 \%$ da carteira total dos clientes do banco. Os entrevistados foram selecionados, aleatoriamente, por meio de uma planilha fornecida pelo Crediamigo. Os dados obtidos foram tabulados em gráficos para proporcionar uma melhor análise quantitativa dos resultados.

Com esta análise metodológica, que, de acordo com Moraes (1990), é um estudo que se refere aos instrumentos de captação da realidade, maneira de atingir determinados fins, buscou-se traçar o perfil dos beneficiados pelo microcrédito, visando a uma melhor compreensão do tema abordado, assim como identificar se o microcrédito de fato repercutiu em melhoria nos níveis de qualidade de vida dos seus beneficiários.

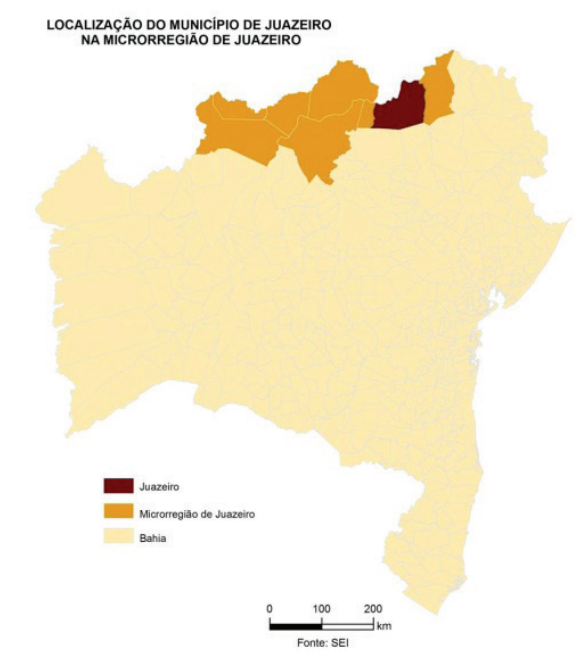

Figura 1 - Localização do município de Juazeiro na microrregião de Juazeiro 


\section{As contribuições do Crediamigo na cidade de Juazeiro, BA}

De acordo com o estudo de caso feito junto à agência do Banco do Nordeste em Juazeiro, BA, acerca do Crediamigo, com base em setembro de 2011, verificou-se que existem 3.572 clientes ativos e que foram realizadas 13.370 operações, com um índice de, aproximadamente, $4,98 \%$ de inadimplência. Após levantamento dos dados adquiridos com alguns desses clientes, foi possível obter informações quanto ao perfil, à finalidade e às melhorias que esse microcrédito proporcionou, tanto no negócio quanto na vida pessoal de cada um.

A pesquisa mostrou que a maioria desses clientes ( $70 \%$ ) é do sexo feminino, conforme gráfico 1 , o que se deve ao aumento do ingresso da mulher no mercado de trabalho e ao fato de a atividade feminina servir como fonte para complementar a renda familiar, já que a maioria das atividades informais (destino principal do microcrédito) é exercida por mulheres e a maioria desse microcrédito é destinado para atividades informais.

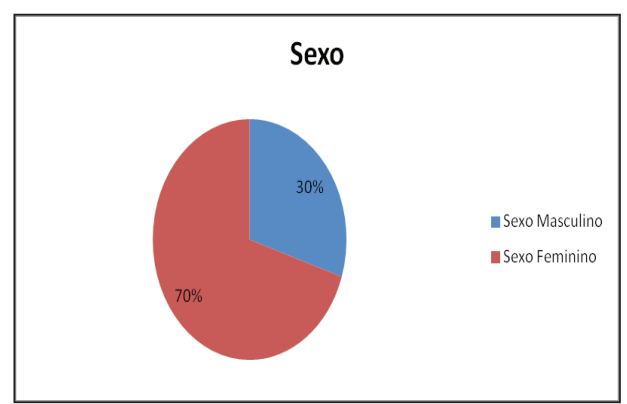

Gráfico 1 - Sexo

Fonte: pesquisa de campo.

Os dados obtidos indicam que a maioria dos entrevistados tem entre 20 e 39 anos, o que não demonstra necessariamente um perfil empreendedor, pois muitos que buscam esse programa também são micro e pequenos empresários que já estão há algum tempo no mercado e que desejam a melhoria e ampliação de seu negócio. $\mathrm{O}$ gráfico a seguir apresenta a faixa etária dos tomadores do microcrédito:

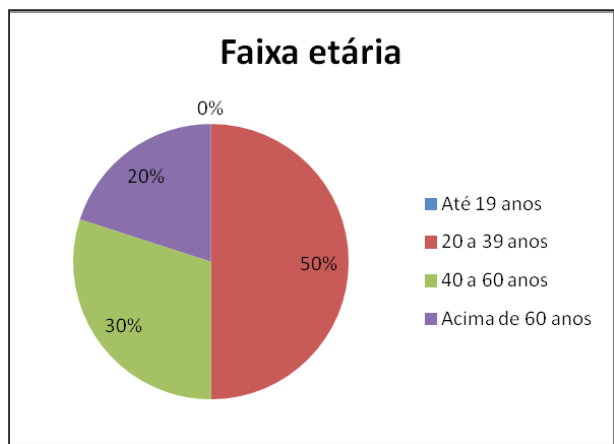

Gráfico 2 - Faixa etária

Fonte: pesquisa de campo.

Com relação ao nível de escolaridade, devido à simplicidade da maioria dos negócios, cerca de $80 \%$ dos entrevistados possuem Ensino Fundamental 15\% Ensino Médio. Esses números demonstram que os beneficiados pelo microcrédito possuem apenas uma formação básica e, provavelmente, apenas conhecimento prático sobre a atividade exercida, o que se torna um ponto crítico, uma vez que essas pessoas podem não ter capacidade para gerir um negócio, como também uma realidade preocupante, por se tratar de atividades informais, que não dão direito aos benefícios e às obrigações de um trabalhador e/ou uma empresa formal. Esse aspecto é retratado no gráfico a seguir:

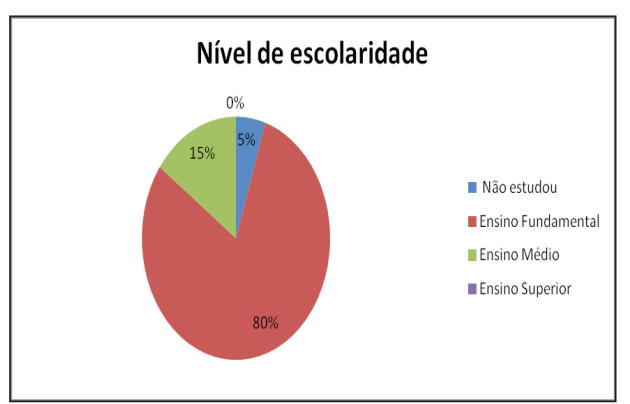

Gráfico 3 - Nível de escolaridade

Fonte: pesquisa de campo.

No que diz respeito ao ramo de atividade, os dados apontam para uma grande variedade de atividades beneficiadas pelo microcrédito fornecido pelo Banco do Nordeste de Juazeiro, conforme mostra o gráfico 4. Pode-se afirmar 
que o ramo de lanchonete ou bar é a atividade que está na liderança, com $37 \%$ dos casos, seguida pelo ramo de vendas, com $21 \%$.

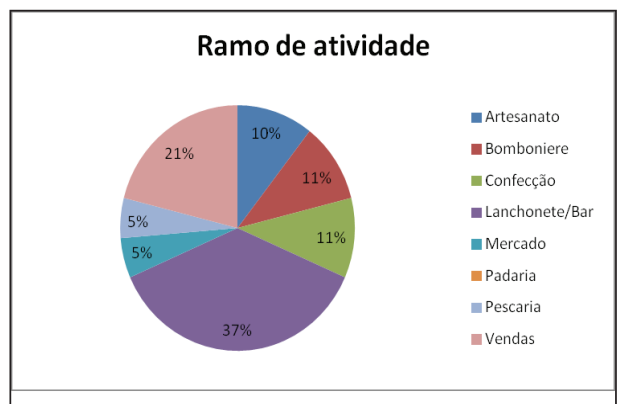

Gráfico 4 - Ramo de atividade

Fonte: pesquisa de campo.

O Gráfico 5 procura identificar o tempo há que o empreendedor está no negócio.

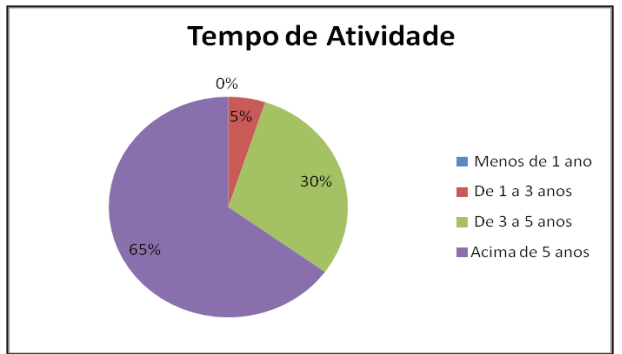

Gráfico 5 - Tempo de atividade

Fonte: pesquisa de campo.

Os dados mostram que $65 \%$ das pessoas estão na atividade há mais de cinco anos e que $30 \%$ estão entre três e cinco anos no negócio. Isto é, o banco, na maioria das vezes, libera empréstimos para pessoas que estão há algum tempo na atividade.

Quanto ao aspecto de geração de empregos para membros da família, o gráfico 5 mostra que, na maioria dos casos $(45 \%)$, apenas uma pessoa da família é beneficiada pelo microcrédito. Além disso, 30\% dos entrevistados não possuem nenhum funcionário. Por outro lado, $25 \%$ dos entrevistados, além de gerar o próprio emprego, contratam até quatro colaboradores para sua atividade.
№ de familiares que trabalham no micronegócio

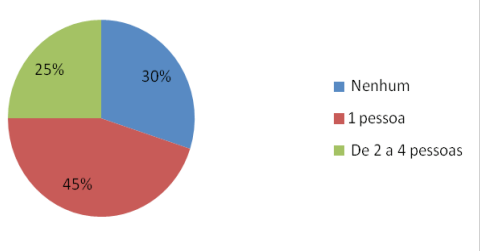

Gráfico 6 - Número de familiares que trabalham no micronegócio

Fonte: pesquisa de campo.

Com relação aos níveis de renda média mensal de cada um dos entrevistados, pode-se verificar uma diversidade, que varia entre $\mathrm{R} \$ 600,00 \mathrm{e}$ $\mathrm{R} \$ 2.000,00$, o que pode ser considerado uma boa renda quando se leva em consideração os níveis de desemprego e os baixos salários pagos atualmente no mercado. Porém, uma renda superior a $\mathrm{R} \$ 3.000,00$ é apresentada pela minoria dos entrevistados, como mostra o gráfico 7 .

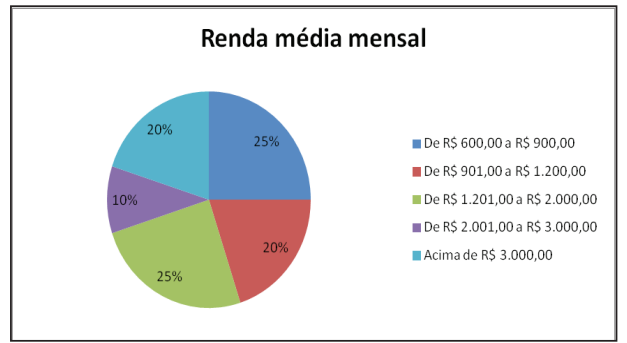

Gráfico 7 - Renda média mensal

Fonte: pesquisa de campo.

Considerando a destinação ou a finalidade do empréstimo obtido, com base nos resultados apresentados no Gráfico 8, podese verificar que a maioria dos entrevistados (95\%) tomou o empréstimo para o capital de giro das atividades, o que demonstra que a destinação do microcrédito é, em sua maioria, para manutenção da atividade que está sendo exercida. Os outros 5\% destinaram o investimento a suas atividades, visando a melhoria ou expansão do negócio. 


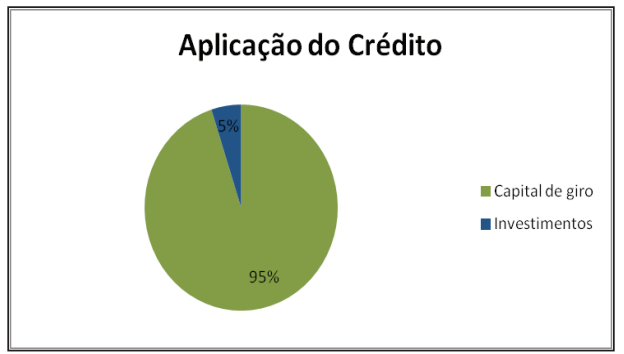

Gráfico 8 - Aplicação do crédito

Fonte: pesquisa de campo.

Quanto às faixas de valores dos empréstimos (Gráfico 8, pode-se constatar que a maioria (45\%) é de valores acima de $\mathrm{R} \$ 2.000,00$, seguido por empréstimos de $\mathrm{R} \$ 1.000,00$ e $\mathrm{R} \$ 2.000,00$.

A instituição empresta valores, na maioria das vezes, acima de $\mathrm{R} \$ 300,00$, o que se torna um ponto positivo, já que empréstimos abaixo desse montante podem trazer prejuízo para a instituição - os custos advindos de avaliação, consulta aos órgãos de proteção ao crédito, visitas ao local do empreendimento e despesas administrativas são superiores ao retorno do empréstimo, isto é, não atingem seu ponto de equilíbrio.

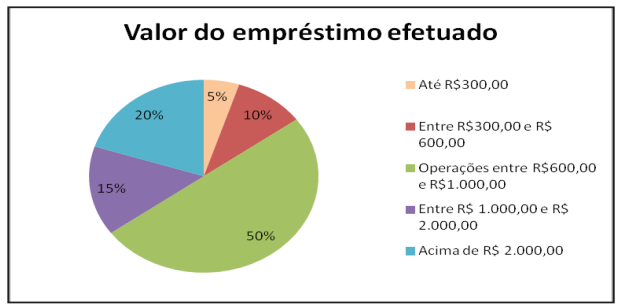

Gráfico 9 - Valor do empréstimo efetuado Fonte: pesquisa de campo.

Outro aspecto analisado na pesquisa se referiu à possibilidade de os empreendedores darem continuidade às suas atividades sem o empréstimo do microcrédito, o que se torna difícil devido ao fato de a maioria não possuir outra fonte de financiamento além da instituição onde foi concedido o empréstimo. O gráfico 10 apresenta o resultado sobre as fontes alternativas de crédito: $50 \%$ dos entrevistados utilizam o microcrédito como fonte de crédito, $25 \%$ como capital próprio e $25 \%$ como empréstimo particular.

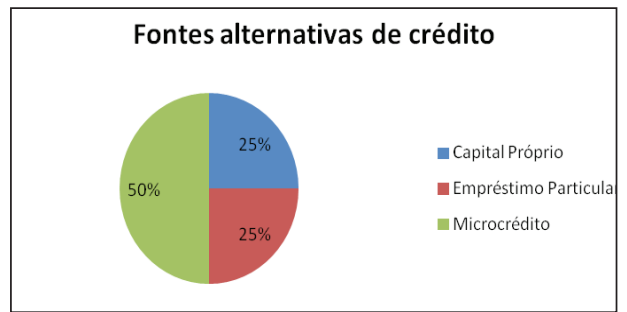

Gráfico 10 - Fontes alternativas de crédito Fonte: pesquisa de campo.

No entanto, o microcrédito constitui-se como uma ferramenta para o desenvolvimento dos negócios, uma vez que apresenta menores taxas de juros, servindo, assim, como uma opção mais viável em termos de custos. Outro atrativo relaciona-se à concessão de crédito assistida pelos agentes de crédito, que acompanham o empreendimento, apresentando as informações necessárias e possibilitando, assim, maior conhecimento e segurança em relação ao negócio. Essas informações confirmam a metodologia de relação com o cliente como a melhor forma de atraí-los. Segundo informações do Banco do Nordeste, há uma relação direta, que permite conhecer a realidade do cliente e, posteriormente, há a oferta de cursos e palestras com o objetivo de proporcionar um melhor aproveitamento dos recursos emprestados. Com isso, nota-se uma diferença em relação às relações impessoais dos bancos tradicionais, que não possuem esse contanto mais direto e preciso.

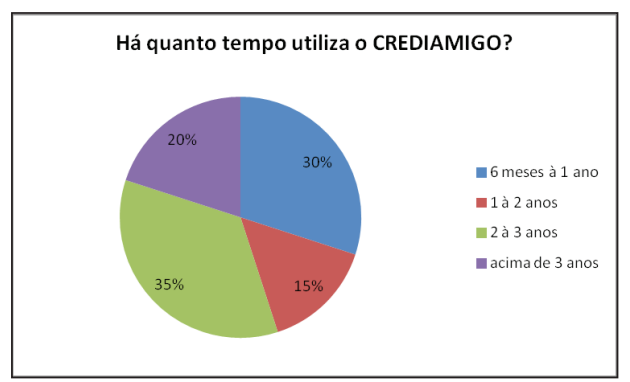

Gráfico 11 - Tempo de utilização do Crediamigo Fonte: pesquisa de campo. 
Quanto ao tempo que os clientes utilizam o crédito do Crediamigo, podese constatar que $35 \%$ dos tomadores são clientes na faixa de 2 a 3 anos, $30 \%$ de 6 meses a 1 ano, 20\% acima de 3 anos e $15 \%$ de 1 a 2 anos, o que demonstra um nível de satisfação dos clientes pois estes dão continuidade às operações, fazendo sempre renovações e se tornando clientes assíduos e fiéis.

O Gráfico 12 mostra a evolução do número de clientes. Após a obtenção do microcrédito, $53 \%$ dos entrevistados afirmaram que houve um expressivo aumento no número de clientes, 34\% tiveram um aumento razoável e apenas $13 \%$ tiveram um pequeno aumento. Porém, não houve registro de ausência de aumento nem de diminuição dos clientes após recebimento do microcrédito.

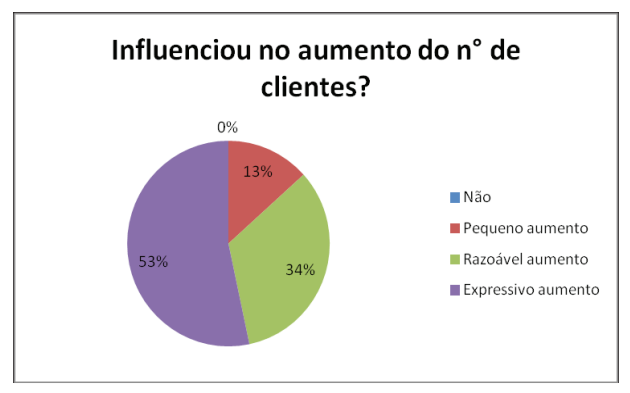

Gráfico 12 - Influência no aumento do número de clientes

Fonte: pesquisa de campo.

Por consequência do aumento de clientes, $80 \%$ dos entrevistados afirmam que o Crediamigo contribui de forma significativa para o aumento das vendas do seu negócio. Os outros $20 \%$ afirmam que a contribuição foi razoável. Não houve nenhum registro de falta de contribuição, o que mostra grande importância desse microcrédito para os pequenos negócios, já que ajuda no seu desenvolvimento e proporciona uma maior venda, como mostra o gráfico 13.

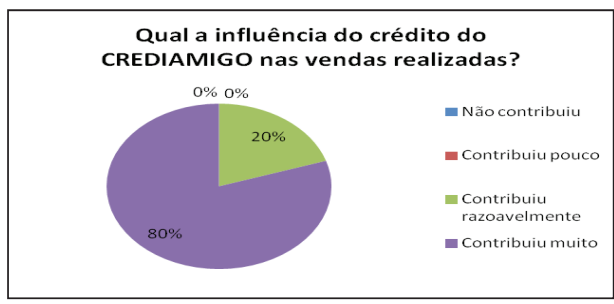

Gráfico 13 - Influência do Crediamigo nas vendas realizadas

Fonte: pesquisa de campo.

Dentre as melhorias ocorridas no negócio/atividade dos empreendedores tomadores do microcrédito, nota-se que o empréstimo permitiu a aquisição de máquinas e outros utensílios, assim como a expansão de seus negócios. Isso confirma a tendência de ampliação da atividade exercida pelo empresário com a aquisição do microcrédito e, consequentemente, um aumento nas vendas, proporcionando, assim, um maior lucro. O gráfico 14 mostra que $73 \%$ dos tomadores de microcrédito do programa Crediamigo obtiveram um expressivo aumento nos lucros e $27 \%$ tiveram um aumento foi razoável, não havendo registro de entrevistados que tenham obtido pouco aumento ou que não tenham tido aumento nenhum nos lucros.

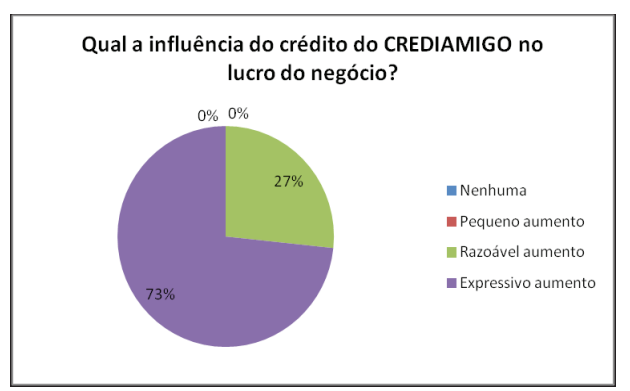

Gráfico 14 - Influência do Crediamigo no lucro do negócio

Fonte: pesquisa de campo. 


\section{Considerações finais}

O estudo realizado acerca do programa de Microcrédito Produtivo Orientado do Banco do Nordeste, Crediamigo, apresenta-o como fator de grande importância para a cidade de Juazeiro, BA, sendo uma alternativa para o desenvolvimento socioeconômico, como também um auxílio às políticas de combate à pobreza, já que não é possível alocar todas as pessoas em ocupações formais. O entendimento no que diz respeito às mudanças causadas aos financiados foi proporcionado quando, na análise dos dados, constatou-se uma evolução para a maioria dos entrevistados quanto ao número de clientes, às vendas e à renda familiar.

É importante ressaltar que os relatos referentes à instituição foram quase sempre de elogios e satisfação, tanto que a grande maioria já indicou, ou indicaria, a instituição, o que evidencia o grau de satisfação dos clientes. Dessa forma, é coerente afirmar que o microcrédito vem desempenhando, com eficácia, seu papel na sociedade e que, realmente, contribui para a mudança socioeconômica na vida dos tomadores do empréstimo.

Os recursos adquiridos, aliados à orientação proporcionada pelo Banco do Nordeste, formam uma conjunção eficaz e necessária para o bom desempenho dos micro e pequenos empreendimentos, criando a expectativa de que o setor informal se abra para a atuação do microcrédito e que as organizações possam, cada vez mais, disseminar a ideia do empréstimo solidário e que possam, também, proporcionar orientação, cabendo aos financiados se comprometerem com o bom desenvolvimento do negócio.

Sendo claras as demonstrações de mudanças ocorridas, bem como de melhorias na atividade exercida dos tomadores de crédito e na sua qualidade de vida, pode-se dizer que o Crediamigo traz oportunidades de desenvolvimento como um todo. Não que esta seja a solu- ção definitiva para combater a pobreza, a exclusão social e o desemprego, mas é, sem dúvida, um grande aliado nesse processo e um instrumento que tem ajudado milhares de pessoas em várias partes do mundo, proporcionando inclusão social, como foi demonstrado através dos resultados da pesquisa relativa à cidade de Juazeiro, BA.

\section{Referências}

1. AGÊNCIA BRASIL (2007). Programa de microcrédito produtivo dobra renda depequenos empreendedores. Disponível em: http://agenciabrasil. ebc.com.br/noticia/2007-09-20/programa-demicrocreditoprodutivo-dobra-renda-de-pequenos-empreendedores-diz-coordenador. Acesso em 20 de setembro de 2011.http://agenciabrasil. ebc.com.br/noticia/2007-09-20/programa-de-microcreditoprodutivo-dobra-renda-de-pequenos-empreendedores-diz-coordenador. Acesso em20 de setembro de 2011.

2. BANCO CENTRAL DO BRASIL (BACEN). Democratização do Crédito no Brasil - Principais Desafios Atuação do Banco Central. Disponível em: http://www.bacen.gov.br. Acesso: 05/04/2011

\section{BANCO DO NORDESTE DO BRA-} SIL S/A - C. Relatório Anual Crediamigo 2010. Disponível em:http://www. bnb.gov.br/content/aplicacao/produtos_e servicos/crediamigo/docs/relatorio $2 \overline{0} 11$ portugues.pdf. Acesso em 10 de Ägosto de 2011.

4. BANCO DO NORDESTE DO BRASIL S/A - A, <http://www.bnb.gov.br>. Acesso em 20 de setembro de 2011.

5. BARONE, F. M.; DANTAS, V.; LIMA, P. F; REZENDE, V. Introdução ao microcrédito. Brasília: Conselho da Comunidade Solidária, 2002.

6. BARONE, F. M. Acesso ao crédito e desenvolvimento local: o microcré- 
dito no Brasil. Rio de Janeiro: Editora FGV, 2003.

7. CAVAlCANTE, A. B. Microcrédito: uma alternativa de crédito produtivo para o micro e pequeno empreendedor. Disponível em: http:// integração.fgvsp.br/ano5/15/index.htm Acesso: 05/04/2011.

8. COELHO, J. M. B.; PRANDINI, E. R. Programa Nacional de Microcrédito Produtivo e Orientado: conquistas e desafios. In: FELTRIM, L.E.; VENTURA, E.C.F.; DODL, A.B.(coords.). Perspectivas e desafios para inclusão financeira no Brasil: visão de diferentes atores. Brasília: Banco Central do Brasil, 2009.

9. GIL, A. C. Como Elaborar Projetos de Pesquisa. 3. ed. São Paulo: Atlas, 1996.

10. GitMan, L. J. Princípios de administração financeira. São Paulo: Harbra,1997.

11. LAKATOS, E. M. Metodologia do trabalho científico: procedimentos básicos, pesquisa bibliográfica, projeto e relatório, publicações e trabalhos científicos / Marina e Andrade Marconi, Eva Maria Lakatos. - 6. ed. - 7. reimpr. São Paulo: Atlas,2006.

12. LEITE, I. C. Novos olhares, novos lugares: por uma política social de combate à pobreza condizente com a construção da cidadania. Convergência - Revista de Ciencias Sociales. Toluca (México), Universidad Autónoma del Estado de México, v. 15, n. 47, p. 73-100, mayo/ago 2009.

13. LEVINE, D. M.; STEPHAN, D. F.; KREHBIEL, T. C,; BERENSON, M. L. 4.ed. Estatística: teoria e aplicações. Rio de Janeiro: LTC, 2000.

14. LOPES, B. M. Análise da evolução do microcrédito na Bahia (19732008). Fortaleza: Banco do Nordeste do Brasil 2011.

15. MAlhotra, N. K. Pesquisa de
Marketing: uma orientação aplicada. Tradução Laura Bocco. $4^{\mathrm{a}}$ edição. Porto Alegre: Bookman, 2006.

16. MATTOSO, J. E. L. Crescimento e Emprego em 2000. Monitor Mercantil, Rio de Janeiro, maio./2000.

17. MARTINELLI, D. P. Desenvolvimento local e o papel das pequenas e médias empresas. Barueri: Manole, 2004.

18. MORAES, I. N. Elaboração da Pesquisa Científica. $3^{\circ}$ ed. Rio de Janeiro:Editora Atheneu, 1990.

19. NERI, M. Microcrédito, o mistério nordestino e o Gremeen brasileiro: perfil e performance dos clientes do CrediAmigo. Rio de Janeiro: Ed. FGV, 2008.

20. SANTOS, A.; GOIS, F. F de. Microcrédito e Desenvolvimento Regional. Fortaleza: Premius Editora, 2011.

21. SERVIÇO BRASILEIRO DE APOIO A MICRO E PEQUENA EMPRESA - SEBRAE (2004). Fatores condicionantes e taxa de mortalidade de empresas no Brasil. Disponível em http://www.bibioteca.sebrae.com.br. Acesso: 20/04/2011.

22. SERVIÇO BRASILEIRO DE APOIO A MICRO E PEQUENA EMPRESA (SEBRAE). O que é microcrédito? Disponível em http://www. sebrae.com.br. Acesso:20/04/2011.

23. VENTURA, E. C. F.; FONTES FILHO, J. R.; SOARES, M. M. (Orgs.). Governança Cooperativa: diretrizes e mecanismos para fortalecimento da governança em cooperativas de crédito. Brasília: Banco Central do Brasil, 2009.

24. YUNUS, M. O Banqueiro dos Pobres. $1^{\text {a }}$ ed. São Paulo, Editora Ática, 2008. 